Portuguese Journal of Political Science | Revista Portuguesa de Ciência Política ISSN: 1647-4090 | ISSN-e: 2184-2078 | 2019, Número 11, Páginas 83-99

DOI: 10.33167/2184-2078.RPCP2019.11/pp.83-99

\title{
Autoritarismo, identidade e terror: as causas da violência etarra
}

\section{Diogo Noivo*}

* Observatório Político, Portugal; diogo.noivo@gmail.com

\begin{abstract}
Resumo
O autoritarismo franquista é frequentemente apresentado como a causa fundamental do terrorismo basco. A inexistência de mecanismos de participação política aliada à pretensa intenção do regime em obliterar a cultura basca e diluir a etnia local através de mecanismos de repressão específicos e direcionados são geralmente apontados como os incentivos determinantes para o aparecimento da organização Euskadi ta Askatasuna (ETA). O presente artigo desafia essa suposição mediante a análise política e historiográfica do momento fundacional da ETA, para em seguida identificar os precipitantes, as pré-condições e fatores permissivos que influenciaram o uso de violência política pela organização.
\end{abstract}

Palavras-chave: autoritarismo; Espanha; ETA; terrorismo; violência política

\begin{abstract}
Francoist authoritarianism is often presented as the root cause of Basque terrorism. The inexistence of mechanisms of political participation along with the regime's purported intention to obliterate Basque culture and dilute local ethnicity through specific and targeted repression mechanisms are usually pinpointed as the key incentives to the emergence of the organization Euskadi ta Askatasuna (ETA). This article challenges that assumption through the political and historiographical examination of ETA's inception, to then identify the precipitants, preconditions and permissive factor that did influence the use of political violence by the organization.
\end{abstract}

Keywords: authoritarianism; ETA; political violence; Spain; terrorism 


\section{Introdução}

Criada em 1959 e oficialmente dissolvida no ano de 2018, a organização terrorista ETA (Euskadi ta Askatasuna - País Basco e Liberdade) foi o produto de um de vários cismas ocorridos no percurso do nacionalismo basco fundado por Sabino Arana (1865-1903) no final do século xıx. A organização, nas suas diversas variantes, é responsável por pelo menos 845 homicídios, por mais de 2500 feridos e por um número indeterminado de cidadãos que, sob ameaça de morte e submetidos a acosso público, foram forçados a abandonar o País Basco (López Romo, 2014). A ETA erigiu-se na História contemporânea de Espanha como um dos principais desafios políticos e de segurança, especialmente durante os períodos de transição e de consolidação democráticas.

Não foi a primeira dissidência no seio do nacionalismo basco nem a primeira a recorrer a um discurso proponente de um confronto armado, mas foi a primeira a outorgar à violência uma função primordial, reiterada e sistematizada na persecução de objetivos políticos, concretamente da independência do País Basco e de Navarra enquanto componentes de uma entidade político-administrativa una e indivisível. Estes objetivos foram enquadrados num marco ideológico de socialismo revolucionário, inspirado pelos movimentos de libertação nacional do então designado "Terceiro Mundo", uma componente ideológica saliente na doutrina e na retórica, mas de relevância menor no plano estratégico quando comparada com as metas puramente nacionalistas.

A natureza autoritária do regime instituído e presidido pelo General Francisco Franco é com frequência apontada como uma das principais causas - quando não a principal causa - da fundação da ETA. A repressão de liberdades políticas, de direitos individuais e coletivos, e sobretudo as várias formas de agressão estatal a expressões culturais e identitárias bascas constituiu para os proponentes deste argumento um estímulo importante à violência política.

Porém, ao estabelecer uma relação simples de causalidade direta, o argumento redunda numa conclusão determinista que oculta a complexidade do fenómeno terrorista. Mais importante, apresenta uma conclusão que carece de sustentação empírica.

Com o propósito de identificar os motivos e as dinâmicas relevantes para o aparecimento de violência terrorista no seio do nacionalismo basco, o presente artigo submete o momento fundacional da ETA ao esquema de fatores permissivos do terrorismo gizado por Martha Crenshaw (1981; 2011). Partindo da premissa que o terrorismo é resultado de um processo de escolha racional e de opções estratégicas, Crenshaw converge diferentes níveis de análise, tanto internos como externos às organizações, para elencar as pré-condições e os catalisadores favoráveis ao aparecimento de violência política na forma de terrorismo. Ao centrar-se em casos que, na sua maioria, são de inspiração nacionalista e revolucionária, o modelo teórico em apreço, um contributo basilar para a investigação às causas do terrorismo, oferece vias com potencial para sinalizar as condições que contribuíram para a criação da ETA. 
Assim, uma vez que o modelo de escolha racional tem como objeto organizações terroristas, na primeira parte deste artigo as características da ETA são contrastadas com os elementos definidores do conceito de terrorismo com o intuito de demonstrar que a organização se insere nesse perímetro conceptual. Na segunda parte, as debilidades do argumento que confere ao autoritarismo do regime Franquista a responsabilidade pela constituição da ETA são identificadas por via de exame dos planos histórico e político. Na terceira parte, os contextos interno, social e político existentes no momento da fundação da ETA são submetidos ao modelo de escolha racional proposto por Crenshaw.

\section{A ETA e o conceito de terrorismo}

Como referido anteriormente, das várias cisões ocorridas no seio do nacionalismo basco a ETA foi a única a recorrer de forma preferencial, sistematizada e rotineira à violência com propósitos políticos. Assim, os conceitos 'independentista' e 'separatista' são insuficientes para compreender e caracterizar a organização, desde logo porque a antecederam outras no espaço do nacionalismo basco que ambicionando também a independência e promovendo a separação político-administrativa do País Basco de Espanha não fizeram da violência um eixo central da sua ação ou da sua identidade coletiva.

Porém, o conceito de terrorismo é problemático. Trata-se de um fenómeno social e político complexo no qual se sobrepõem aspetos locais e dinâmicas transfronteiriças. Abrange grupos de origens, épocas e geografias diferentes. Tem associada uma carga política que condiciona quem o observa. Contudo, reconhecendo as dificuldades inerentes à definição, sobretudo as que decorrem de apreciações éticas e morais, mediante abordagens de Política Comparada vários autores balizaram as fronteiras conceptuais do fenómeno terrorista com precisão suficiente para constituírem trabalhos seminais e, como tal, referências indispensáveis a qualquer aproximação ao tema. Para os efeitos do presente artigo, e dado que o objeto de análise é a organização ETA, a abordagem conceptual que se segue considera somente formas de terrorismo não-estatal, ou sub-estatal.

O terrorismo é uma tática que quando empregue de forma constante e preferencial assume um carácter estratégico. Hoffman (2006, pp. 1-3) caracteriza-o como um fenómeno fundamental e inerentemente político onde a violência, ou a ameaça do seu uso, constitui um instrumento para a aquisição e uso do poder com o intuito de alcançar mudanças na estrutura e distribuição de poder político, fazendo notar igualmente que se trata de ações planeadas, calculadas e sistematizadas. Concordando com a natureza política e premeditada do fenómeno, Reinares (1998, pp. 15-16) acrescenta que a violência terrorista se verifica quando o alcance físico da violência é inferior ao efeito psicológico que provoca e às alterações que introduz no quotidiano de uma sociedade. Por outras palavras, quando a ansiedade e o medo sentidos pela sociedade na sequência de um ato violento superam de forma desproporcional os danos materiais e humanos causados. O objetivo último é o de inocular 
o temor na sociedade com o propósito de condicionar atitudes e dirigir comportamentos sociais e políticos.

Assim, tal como Reinares, Gibbs (1989), Crelinsten (2002) e outros notam que os alvos diretos da violência não são os seus reais destinatários. Na senda de condicionar comportamentos, a violência terrorista serve-se dos alvos diretos para veicular uma mensagem destinada a coagir e a lograr obediência de um segundo conjunto de alvos (o Estado e as suas instituições), bem como a intimidar e impressionar uma audiência mais vasta (a opinião pública). A este respeito, Alex P. Schmid (2004) defendeu que as vítimas desempenham uma função meramente instrumental, são a pele de um tambor que é percutida para atingir um impacto calculado numa audiência ampla.

Juntamente com Albert J. Jongman, Schmid (1988) é autor da definição porventura mais abrangente de terrorismo, e que maior impacto teve nos estudos sobre o fenómeno. Nela são referidas as características anteriormente enunciadas, declinando a importância relativa das vítimas diretas para a organização terrorista numa observação pertinente: as vítimas diretas são frequentemente alvos de oportunidade, escolhidas com base num racional custo-benefício. São indivíduos cuja identidade pessoal ou profissional os torna parte do inimigo - nos termos em que a organização terrorista o define - , podendo, no entanto, tratar-se de figuras menores na estrutura a atacar, gente vulnerável cuja única relevância é simbólica.

A organização ETA insere-se plenamente na conceção de terrorismo agora apresentada. No domínio estratégico, onde se situa a opção do uso preferencial e reiterado da violência para fins políticos, a ETA aprovou na IV Assembleia, realizada em 1965, a política "acción-reacción-acción" cujo sentido era o de provocar, por via da violência, uma resposta desproporcional das autoridades do Estado sobre a população e, assim, validar o discurso de vitimização e obter o respaldo da sociedade que a organização dizia representar com vista a obter dividendos políticos. As etapas são detalhadas no documento aprovado sob o título "Bases teóricas de la guerra revolucionária":

I. A ETA, ou as massas dirigidas pela ETA, realizam uma ação provocadora contra o sistema;

II. O aparelho de repressão do Estado golpeia as massas;

III. Face à repressão, as massas reagem de duas formas opostas e complementares: com pânico e com rebeldia. É o momento adequado para que a ETA dê um contragolpe que diminuirá o primeiro e aumentará a segunda (Fernández Soldevilla \& López Romo, 2012, pp. 25-26).

A “acción-reacción-acción" passou por diversas fases de intensidade, determinadas pelos contextos sociopolíticos e por variações na capacidade operacional da organização ao longo do tempo, mas o racional a ela subjacente foi uma constante durante os anos de atividade da ETA. Os visados foram na sua maioria - mas não exclusivamente - representantes do Estado como, por exemplo, membros das forças e serviços de segurança, guardas prisionais, magistrados judiciais, governadores 
civis e militantes dos partidos tidos como "españolistas", historicamente o Partido Socialista Obrero Español (PSOE) e o Partido Popular (PP) - antes deste último, também a Unión de Centro Democrático (UCD) constou da lista de alvos políticos da organização.

A partir de meados da década de 1990, já em plena vigência da Constituição democrática aprovada em 1978, ocorre uma adaptação estratégica na qual, em paralelo ao que foi delineado na IV Assembleia, é assumida a abertura do leque de opções de vítimas diretas da violência, uma etapa conhecida como "socialização do sofrimento": jornalistas, académicos, empresários e todos aqueles que se opusessem à organização e aos seus objetivos passaram a ser alvos explícitos. A partir deste momento intensifica-se também a kale borroca [violência urbana de baixa intensidade perpetrada por grupos organizados afetos à ETA] que, entre outros objetivos, pretendia condicionar o nacionalismo basco moderado e persuadi-lo a aceitar os propósitos políticos da organização. Ao aumentar a variedade de perfis de vítimas, a ETA potenciou a pressão exercida sobre o Estado, coagiu aqueles que entendia estarem obrigados a respaldar os seus objetivos, e, no geral, amplificou o medo instigado na sociedade.

Um estudo ao perfil das vítimas assassinadas pela ETA segmenta-as em atentados anteriores à "socialização do sofrimento" (1978-1994) e posteriores (1995-2003), concluindo que neste último período se verificou um decréscimo do número de mortos pertencentes às Forças e Serviços de Segurança - de 45.2\% do total para 20.9\% - e um aumento significativo de políticos e representantes civis do Estado - de 1.6\% do total para 29.1\% (De la Calle \& Sánchez-Cuenca, 2004, pp. 64-65). Verificou-se também um decréscimo no número de vítimas mortais civis, - de $34.5 \%$ do total para $29.1 \%$ - tendência que muito provavelmente seria diferente se o estudo contemplasse feridos, ameaçados, sequestrados e extorquidos, uma vez que os atos de intimidação foram estruturais na atuação da ETA sobre civis sem vinculação institucional ao Estado.

É o que sugerem os dados da Guardia Civil [gendarmaria espanhola] para os anos compreendidos entre 1968 e 2001. Sendo incompletos e a requerer estudo detalhado, estes dados revelam que a ETA recolheu informação sobre 1843 empresários, o que compara com 733 militares da Guardia Civil, 899 membros da judicatura e 61 membros da Fiscalía (López Romo, 2014, pp. 112-114). Somando escritores, membros de universidades, profissionais dos órgãos de comunicação social e ativistas do Foro de Ermua [organização pacifista da sociedade civil], a ETA recolheu informações sobre 707 indivíduos (López Romo, 2014, pp. 112-113).

Ainda no que respeita ao perfil das vítimas, a ETA revelou apetência por alvos com maior exposição e, portanto, mais vulneráveis. Visou elementos da Guardia Civil, do Cuerpo Nacional de Policía [força de segurança civil], das polícias autonómicas e das polícias municipais que, na sua maioria, desempenhavam funções de patrulha ou equiparáveis, se encontravam em momentos de lazer sem escolta armada, ou em situação de aposentação. 
Quanto a militantes de partidos políticos, a propensão foi em tudo semelhante. Muito embora tenha atentado contra indivíduos em posições de relevo, como a presidência de municípios e a Chefia do Governo, a ETA atentou com frequência contra indivíduos sem influência nas estruturas nacionais dos respetivos partidos, por vezes até com uma ascendência diminuta nas estruturas partidárias locais e, por isso, sujeitos a poucas ou nenhumas medidas de segurança pessoal. Nesta tipificação de vítima, os militantes jovens sobressaem. Dois dos casos mais célebres são o de Miguel Ángel Blanco, vereador pelo PP no município de Ermua, em Biscaia, sequestrado e assassinado em 1997 aos 29 anos de idade, e o de Eduardo Madina, membro das Juventudes Socialistas do País Basco, a quem foi colocado um engenho explosivo no carro em 2002, quando tinha 26 anos de idade, tendo a explosão provocado ferimentos vários e a amputação de uma perna.

Casos existem onde o alvo de oportunidade coincidiu com o objetivo de interferir em processos eleitorais mediante atos de violência. Isaias Carrasco foi vereador do Partido Socialista Basco no município de Mondragón-Arrasate, em Guipúscoa, funções que abandonou em 2007 para trabalhar como portageiro numa autoestrada. Carrasco prescindiu da escolta armada a que tinha direito e foi assassinado a tiro no último dia da campanha eleitoral para as legislativas de Março de 2008.

De resto, o caso de Carrasco é paradigmático do uso da violência em momentos eleitorais. O estudo empírico da variação temporal da letalidade das ações da ETA revela contextos específicos de maior concentração de vítimas mortais, nomeadamente os períodos que antecedem eleições legislativas e municipais (Sánchez-Cuenca, 2009). Não se verifica a mesma tendência em vésperas de eleições europeias, percebidas como sendo de menor importância para a vida interna de Espanha, e de eleições regionais - trata-se da eleição de representantes para instituições bascas e, como tal, a hipótese avançada é a de que a organização foi consciente do potencial efeito contraproducente do uso da violência (Sánchez-Cuenca, 2009). Existem, porém, importantes exceções: em 1980, ano em que se celebraram as primeiras eleições autonómicas bascas e em que se formou o primeiro parlamento basco, a ETA e as organizações a ela associadas foram responsáveis pela morte de 96 pessoas, o que dá uma média de uma vítima mortal, a cada 3,6 dias.

\section{O autoritarismo franquista enquanto causa da violência política etarra}

A natureza autoritária do regime franquista é com frequência apontada como a principal razão do aparecimento da ETA e do recurso à violência como instrumento de ação política. Este argumento foi inaugurado pela própria organização em comunicados e em suportes propagandísticos. No boletim Zutik, Julen Madariaga (1961), um dos fundadores da ETA, arguiu: "A nossa política de defendermo-nos da violência do tirano ocupante por meio da VIOLÊNCIA ( sic) não a escolhemos nós, os bascos: foi-nos imposta". Nos termos da exegese etarra, o regime não deixava alternativas.

Além da repressão rotineira e estrutural por parte do Estado, estaria também em causa um plano genocida espanhol destinado à exterminação étnica e cultural do 
povo basco uma vez que, na interpretação feita pelo nacionalismo radical, a Guerra Civil foi em grande medida um confronto com antecedentes seculares entre Espanha e o País Basco.

A audácia demonstrada nos primeiros anos de "luta armada" e o cuidado inicial em apenas visar membros do regime e das Forças de Segurança conferiram à ETA uma aura mítica que colheu junto da população e mereceu a simpatia de setores democratas liberais. O processo de Burgos, o tribunal militar que no final de 1970 condenou vários membros da ETA à pena capital, uniu e reforçou os pressupostos deste argumento. Muito embora as penas de morte fossem comutadas, a pressão popular e política sobre o regime vinda de dentro e de fora de Espanha converteram a organização terrorista num símbolo da repressão sofrida por todos os espanhóis, e em particular pelos bascos. O autoritarismo do Estado espanhol foi assim colocado na génese da organização, uma tese que enquadra o advento da violência etarra no âmbito de uma resistência legítima ao poder ditatorial, transferindo, portanto, o ónus ético e moral dos atentados para o Estado.

Descontando os trabalhos pretensamente académicos cujo único ânimo foi ideológico e de combate cultural, alguns historiadores, jornalistas e políticos deram continuidade à tese da resistência legítima por falta de dados empíricos sobre a repressão franquista no pós-Guerra Civil e porque, porventura, foram alvo de 'presentismo': transladaram a sua experiência de testemunhas da opressão estatal no final da década de 1960 e princípio da década de 1970 para um passado que não conheceram de forma direta (Zubiaga Arana, 2017; Fernández Soldevilla, 2014).

O racional implícito à tese da resistência legítima defende que, por se socorrerem da repressão e da coação para lidar com projetos políticos alternativos, os regimes autoritários empurram as vozes dissonantes para as franjas da arena social e política, um agravo que gera sentimentos atendíveis de injustiça, frustração e alienação que, por sua vez, constituem estímulos à violência.

Esta lógica é validada por alguma da literatura especializada. A título de exemplo, Beatrice de Graaf e Leena Malki (2010) subscrevem esta abordagem de forma tácita e matizada ao arguir que a vida efémera da Rode Jeugd (Juventude Vermelha), organização terrorista de extrema-esquerda que operou na Holanda na década de 1970, se deveu, entre outros fatores, ao pluralismo do sistema político holandês e à inexistência de opressão estatal ostensiva. No plano teórico, quanto ao aparecimento de violência política no geral, autores como Lipset (1963) e Huntington (1965) situam a fonte da violência sub-estatal, respetivamente, na ilegitimidade do poder institucional em exercício e no desequilíbrio entre a procura e a oferta de bens políticos, como sejam as liberdades individuais ou o reconhecimento de identidades comunais.

Aplicando este racional ao País Basco, as décadas de acosso policial sobre a população, de proibição de direitos políticos e de liberdades individuais, as detenções, as sevícias, e sobretudo a tentativa de extermínio da cultura e identidade locais por parte de um regime que pretendeu homogeneizar Espanha mediante a eliminação de nacionalismos periféricos, como o catalão ou o basco, não só explicarão o apa- 
recimento da ETA enquanto organização revivalista do nacionalismo basco como justificarão o recurso às armas. Apesar do apelo intuitivo do argumento e da sua eventual validade na explicação da origem de determinados casos de violência política sistematizada, no caso do terrorismo basco ele resiste mal ao escrutínio histórico e político.

Em primeiro lugar, a repressão do ramo radical do nacionalismo basco por parte do Estado não foi uma inovação da ditadura franquista. Ainda que com graus diferentes de intensidade consoante a etapa histórica em apreço, o nacionalismo basco radical foi submetido a acosso e a repressão estatal desde o momento em que Sabino Arana o fundou no final do século XIX, um arco cronológico que compreende os regimes da Restauración (1874-1931) - incluindo a etapa da Ditadura de Primo de Rivera (1923-1930) - e da II República (1931-1939). O próprio Arana, os seus correligionários e seguidores cumpriram penas de prisão efetiva, viram símbolos nacionalistas destruídos e assistiram reiteradamente ao encerramento compulsivo dos seus locais de encontro e da imprensa nacionalista. Nunca este quadro de agressão estatal continuada deu origem a violência política de carácter estratégico e continuado.

Em segundo lugar, o alcance da repressão franquista durante e após a Guerra Civil não sustenta o cânone de um genocídio cultural e étnico no País Basco. Trabalhos recentes começaram a colmatar a ausência de estudos detalhados sobre o grau e tipos de opressão nas províncias bascas e as conclusões inviabilizam a alegação segundo a qual as forças insurretas e, posteriormente, o regime franquista tentaram uma limpeza étnica e identitária do povo local. O total de mortos no País Basco rondou os 1500-1800, números consideravelmente inferiores à média nacional (Espinosa Maestre, 2009; Molina, 2014). A análise comparativa demonstra que o número de mortos na cidade de Sevilha é superior ao verificado em todo o País Basco; em Huelva, na Andaluzia, o número de vítimas mortais às mãos do franquismo foi o triplo do verificado em Biscaia, no País Basco, facto relevante se se tiver presente que, à época, as duas províncias contavam com uma dimensão demográfica equiparável (Molina, 2014). Até em regiões onde a resistência ao avanço das forças contrarrevolucionárias foi menor, como La Rioja, Burgos e Navarra, se verificou um número superior de mortes (Espinosa Maestre, 2009). Atendendo às listas de executados e comparando-as com o número de habitantes de cada região, a percentagem de vítimas mortais no País Basco ronda os 0,16\%, das mais baixas em Espanha (Zubiaga Arana, 2017). Considerando outras formas de punição, averiguou-se que os saneamentos na Administração Pública e em empresas privadas foram mais intensos sobre republicanos e sindicalistas do que sobre nacionalistas bascos (Barruso, 2005). Mesmo olhando para o período de ditadura após a criação da ETA, percebemos que das 16 execuções levadas a cabo em Espanha entre 1960 e 1975 apenas duas foram de indivíduos vinculados ao País Basco: Juan Paredes Manot, alias Txiki, e Ángel Otaegi, ambos membros da ETA, mortos pelo regime em 1975 (de Pablo, 2018).

Em suma, o País Basco não foi das regiões mais fustigadas pela violência franquista durante e após a Guerra Civil, sobretudo quando comparado com a Andaluzia 
ou a Estremadura, regiões onde não surgiram organizações comparáveis à ETA. A ditadura nunca esteve empenhada no genocídio étnico e identitário dos bascos, mas sim na perseguição, repressão e estigmatização de dissidentes e opositores, independentemente do seu lugar de origem ou de professarem nacionalismos periféricos, ideais republicanos e anarquistas, ou simplesmente valores democráticos (Fernández Soldevilla, 2014; Zubiaga Arana, 2017).

Por outro lado, e não obstante a intolerância estrutural do regime face a nacionalismos periféricos, o Franquismo passou por períodos de liberalização política controlada com impacto tangível no País Basco. Obtida a vitória militar e consolidado o Nuevo Estado, entre a década de 1950 e as primeiras ações da ETA no final da década seguinte o regime mostrou leniência em relação a manifestações públicas da identidade basca de natureza abertamente nacionalista. Assistiu-se a uma proliferação de livros escritos em euskera, o idioma autóctone. Entre 1960 e 1969 foram publicadas 592 obras em euskera, praticamente o mesmo número de títulos publicados nos 20 anos que antecederam a Guerra Civil (de Pablo, 2018). Ainda no que respeita à língua, importa referir a criação de uma rede de iskatolas, estabelecimentos de ensino onde a educação é ministrada em euskera, o primeiro dos quais, inaugurado em 1954. Num âmbito cultural mais vasto, note-se a fundação em 1964 da Biblioteca Basca, hoje Fundação Sancho el Sábio, o mais completo acervo de cultura local e de alguns materiais provenientes dos anos fundacionais do nacionalismo basco.

Estes e outros sinais de abertura à cultura basca são especialmente relevantes uma vez que Sabino Arana definiu o idioma como um dos principais sustentáculos da sua doutrina. O euskera tem um valor político intrínseco para o aranismo pois, ao ter poucos pontos de contacto com outros idiomas, a sua mera existência permite atestar a singularidade do povo ${ }^{[1]}$.

Nos termos da doutrina nacionalista basca inicial, a língua era igualmente importante enquanto impedimento à degenerescência racial e cultural. Os espanhóis não-bascos eram designados pelo aranismo como maketos, termo pejorativo que se referia a uma raça tida como inferior e hostil. Pilar do nacionalismo basco originário, a par do catolicismo tradicionalista e da defesa do euskera, o antimaketismo é a manifestação mais virulenta do ódio de Arana a Espanha e do seu desprezo pelos imigrantes espanhóis residentes no País Basco. Simultaneamente, foi um veículo para a exaltação da raça basca (Granja Sainz, 2006; De Pablo, 2015). Segundo Sabino Arana (1887), "[o] roçar do nosso povo com o espanhol provoca imediata e necessariamente na nossa raça a ignorância e a perda de inteligência, a fraqueza e a corrupção do coração".

1. Não existe consenso sobre a origem do euskera. A hipótese mais plausível situa o seu aparecimento por volta de 58 a.C. na Aquitânia, região que correspondia grosso modo ao País Basco francês. O euskera primordial resultará do encontro dos povos locais com o Império Romano. Ao contrário do que defende parte do nacionalismo basco radical, não teve origem em épocas pré-históricas nem se manteve livre de influências de outros povos ao longo dos séculos. 
O euskera era, portanto, uma forma de conter a "infeção":

Se nos dessem a escolher entre uma Biscaia povoada de maketos que apenas falassem Euskera e uma Biscaia povoada de biscainhos que apenas falassem castelhano, escolheríamos sem dúvida esta segunda. (...) Os biscainhos estão tão obrigados a falar a sua língua nacional como a não ensiná-la aos maketos (...) a linguagem é o grande meio para nos preservarmos do contágio dos espanhóis e evitar o cruzamento das raças (Arana, 1895b).

A par da preservação racial e cultural, a língua era também um veículo privilegiado para a construção da pátria basca, o que era significativo uma vez que até finais do século XIX não existiam correntes de pensamento estabelecidas que definissem o País Basco como uma nação e que pugnassem pela sua independência. Logo, com o intuito de criar uma consciência coletiva e um sentimento nacional, Arana (1899) propõe:

(...) fundemos sociedades puramente vascongadas [bascas], escrevamos jornais vascongados, criemos teatros vascongados e até instituições benéficas vascongadas. Que tudo quando vejam os nossos olhos, oiçam os nossos ouvidos, fale a nossa boca, escrevam as nossas mãos, pensem as nossas inteligências e sintam os nossos corações seja vascongado (Arana, 1899).

O significado político do idioma foi sintetizado pelo próprio Arana (1895a): "Como sabeis, Euskaldunes [indivíduos étnica e culturalmente bascos], para amar o Euskera tereis que odiar Espanha!".

A abertura do Franquismo a manifestações culturais e, em particular, linguísticas demonstra que o período no qual a ETA foi fundada não foi uma época de eliminação cultural. Pelo contrário, revela que o regime contemporizou com aspetos identitários que eram estruturais para o nacionalismo basco, espaço político e social no qual a organização terrorista se inseriu e dizia defender.

Parte da explicação desta abertura reside no enorme peso da Igreja e do catolicismo tradicionalista tanto no Franquismo como no nacionalismo basco. Ambos se erguiam sobre noções de ordem social e disciplina, de moralidade pública católica, de visões corporativas das relações laborais e sociais, de entendimentos semelhantes do papel da religião e da nação. Ambos viram com desagrado as derivas anticlericais da II República. Esta convergência parcial de bases ideológicas e culturais fez com que os nacionalistas bascos beneficiassem de uma reintegração social e de uma inclusão no sistema político no pós-Guerra mais fáceis do que outros derrotados na Guerra Civil, como os republicanos, os anarquistas e os sindicalistas (Molina, 2014; Zubiaga Arana, 2017).

Em terceiro lugar, a par do escrutínio histórico, importa analisar brevemente o percurso das ideias políticas. A ETA é legatária das alas radicais do nacionalismo basco, personificadas, entre outros, no Partido Nacionalista Basco Aberriano (19211930) e no coletivo Jagi-Jagi (1934-1937), para as quais a natureza do regime político sedeado em Madrid foi sempre irrelevante no plano doutrinário. Esta tradição polí- 
tica define Espanha - e não os regimes de turno - como o inimigo absoluto, como uma ameaça existencial. Como tal, ainda que quase sempre no plano discursivo, foram tecidos vários planos de levantamento armado contra Madrid, e os apelos ao derramamento de sangue em nome da pátria basca e contra Espanha foram um recurso retórico habitual. Isto é, o objetivo foi sempre o de obter a independência, uma meta autónoma da legitimidade, transparência e pluralismo da forma de governo em vigor. Todas as considerações sobre tipos, formas e organização do exercício do poder político se subordinaram ao objetivo cimeiro da separação político-institucional do País Basco do Estado espanhol.

Por fim, na análise à validade do argumento da resistência legítima acresce um importante dado estatístico: apenas 5\% das vítimas mortais causadas pela ETA se situam no período de vigência do regime tutelado pelo Caudillo, com a maior incidência de assassinatos a situar-se nas etapas de transição democrática (1976-1981) e de consolidação da democracia (1982-1994) (López Romo, 2014). Nestas etapas, bem como na última fase de violência etarra (1995-2010), constam entre vítimas indivíduos que foram destacados opositores ao Franquismo, como Ernest Lluch, militante do PSOE e Ministro da Saúde no primeiro Governo de Felipe González, que enquanto académico na época franquista foi várias vezes repreendido, detido e até expulso da universidade por condenar a ditadura.

É certo que o Franquismo tornou eficaz a tática de "acción-represión-acción", validando o discurso de vitimização segundo o qual existia um País Basco ocupado por Madrid, contribuindo assim para consolidar os laços sociais que uniram comunidade nacional imaginada pelo radicalismo nacionalista basco. É igualmente certo que o regime assentou o seu poder político na repressão de dissidência e de opositores. Foi, no entanto, um instrumento que a ETA colocou conscientemente ao serviço de uma estratégia, e não a sua causa.

\section{O caso etarra $v i s-\grave{a}$-vis os fatores permissivos e os catalisadores de violência terrorista}

Como resultado de uma análise comparada a diferentes casos de terrorismo, e considerando apenas organizações clandestinas cujos atos de violência premeditada visaram o Estado com o propósito de alterar a distribuição e a estrutura de poder, Martha Crenshaw $(1981 ; 2011)$ identificou e sistematizou padrões históricos, mínimos denominadores comuns, com influência causal.

Importa, no entanto, distinguir a influência causal entre a direta e a permissiva. A diferenciação deve-se a duas ordens de razão. Por um lado, as condições sociais, políticas, económicas e culturais existentes no momento em que ocorre a criação de uma organização terrorista afetam um vasto conjunto de pessoas, embora apenas uma ínfima parte desse conjunto decida atuar coletivamente com recurso à violência. Esta desproporção requer da análise a recusa de lógicas rígidas de causalidade. Por outro lado, as interpretações ancoradas em relações causais diretas tendem a desprezar o livre arbítrio. 
Os padrões identificados no estudo comparado de Crenshaw são transpostos para um modelo teórico que elenca diferentes tipos e níveis de causalidade com base na sua capacidade explicativa do terrorismo, entendido como um fenómeno político iniciado por um ator racional - a organização. Num primeiro patamar estão as pré-condições, o conjunto de fatores que criam um contexto favorável ao aparecimento a prazo de terrorismo e que, por sua vez, se subdividem em permissivas - que criam oportunidades para a ocorrência de violência terrorista - e em situações que inspiram e motivam campanhas de terrorismo. Num segundo patamar, os precipitantes, ou catalisadores, acontecimentos específicos que precedem a ocorrência de terrorismo - as razões do terrorismo. Diferentes formas de concatenação de condições e fatores dos diversos níveis constituem, então, influências causais permissivas à ocorrência de terrorismo.

A modernização e a urbanização, que produzem um conjunto de aspetos de inter-relação complexa, são a primeira pré-condição permissiva sinalizada por Crewshaw. A relevância desta condição reside, essencialmente, na transformação económica e nas tensões sociais operadas pela modernização, na facilitação do anonimato permitida pelos centros urbanos, nas redes de circulação que tornam a mobilidade mais eficaz, na variedade e disponibilidade de alvos de violência e de recrutamento, bem como por potenciar a publicidade dos atos perpetrados.

De facto, a ETA surge na cidade de Bilbao, e não nas zonas rurais que o nacionalismo basco mitificou na psique coletiva como um símbolo do modus vivendi prístino e puro, tipicamente basco. Muito embora a ETA tenha posteriormente desenvolvido a capacidade de explorar as vantagens táticas e estratégicas de zonas com baixa densidade demográfica, nomeadamente para funções de refúgio e de ocultação de armamento e de explosivos, o cerne da violência e as bases operacionais dos comandos (células) centraram-se em cidades e em territórios eminentemente urbanos.

Ademais, a organização nasce durante uma de várias vagas de industrialização e urbanização do País Basco, o que estabelece um paralelismo com as origens do nacionalismo basco, situadas também num período de intenso desenvolvimento industrial e económico.

Esta semelhança põe em evidência outra das condições permissivas sinalizadas por Crenshaw: a pré-existência de hábitos sociais e tradições culturais que caucionem o recurso à violência contra o Estado, atestando a sua legitimidade política e moral. O itinerário doutrinal proposto por Sabino Arana foi, em grande medida, uma reação negativa à modernidade, fundada no ódio declarado a Espanha. Concretamente, foi uma reação à transformação da paisagem, à chegada massiva de emigrantes oriundos de outras partes de Espanha em busca de trabalho nas indústrias e no setor mineiro e, decorrente deste movimento demográfico, uma reação aos novos costumes e tradições que gradualmente se foram inserindo na região.

Por isso, o aranismo está imbuído de um sentimento agónico de perda face a uma "invasão", o que se reflete numa defesa férrea e virulenta de elementos tradicionais (catolicismo tradicionalista e idioma) e na exaltação da supremacia da raça 
basca - como brevemente demonstrado pelos exemplos citados na secção anterior do presente capítulo. Espanha e os espanhóis são definidos por Arana como invasores hostis, como inimigos apostados na degenerescência cultural e racial dos bascos, o que legitimava a resistência. Algumas das organizações e partidos radicais que sucederam a época fundacional do nacionalismo, como os já referidos Partido Nacionalista Basco Aberriano e o coletivo Jagi-Jagi, definiram o dever basco de resistência a Espanha em termos assumidamente belicistas, contribuindo para consolidar um corpus doutrinário e ideológico que caucionava o recurso à violência. António Elorza (2009), sem nunca aventar uma explicação uni-causal do terrorismo etarra, deteta a origem doutrinária da ETA na cultura de ódio inaugurada por Arana e desenvolvida por organizações nacionalistas subsequentes, o que faz com que, no plano das ideias, a ETA tenha surgido muito antes da sua fundação oficial.

Esta tese assenta em factos e elementos doutrinários refletidos, por exemplo, nos escritos de Santiago de Meabe (1878-1961), integrante do círculo próximo a Sabino Arana, que nos seus anos de juventude assinava com o pseudónimo "Geyme" (Gora Euzkadi y muera España - Força País Basco e morra Espanha). Após a morte de Arana, numa época de adaptação do Partido Nacionalista Basco (PNV) à via legal e à inserção no quadro político partidário em vigor, Santiago Meabe permaneceu um ortodoxo da doutrina aranista inicial e ansiava por um futuro de repressão espanhola ostensiva que suscitasse o levantamento popular definitivo pela independência. Para tal, Meabe definiu três etapas: a "prisão preventiva", o "presídio maior" e o "fuzilamento de patriotas", fase última que faria os bascos entenderem que "havia chegado a hora da Liberdade" (Elorza, 2006; pp. 50-51). O paralelismo com a estratégia "acción-represión-acción" é evidente.

Este lastro doutrinário que antecede a fundação do terrorismo etarra atesta, no caso em apreço, a necessidade identificada por Crenshaw da pré-existência de uma cultura de violência e, a um só tempo, salienta outra pré-condição, a presença de ressentimento acentuado num subgrupo identificável da sociedade que seja motivado por uma perceção de discriminação. Com o cuidado de salvaguardar que não é possível determinar com base neste catalisador uma relação de causalidade única, simples e direta, a autora refere que a violência terrorista é muitas vezes um recurso encontrado por uma fação extremista para satisfazer exigências de vingança e oferecer um caminho para suplantar sentimentos de humilhação. $\mathrm{O}$ nacionalismo basco assenta precisamente numa perceção de humilhação e de injustiça provocadas por Espanha, com a ETA a apresentar-se como a vanguarda armada que corrigiria esses despeitos e devolveria ao País Basco a soberania que alegadamente teve em épocas imemoriais.

Sobre a fação fundadora, Crenshaw nota que o terrorismo é essencialmente um assunto de elites descontentes. Aventa inclusivamente que haverá maior probabilidade da ocorrência de terrorismo quando a passividade das massas coincide com a insatisfação das elites. De facto, a origem imediata da ETA encontra-se no Ekin, um grupo intelectual de universitários oriundos das classes média e alta que pretendia 
recuperar a pureza original da doutrina nacionalista basca e sistematizar os seus elementos históricos, sociais e culturais. Mais importante, este labor foi desenvolvido por se entender urgente a salvaguarda dos patrimónios político e cultural bascos face ao que percebiam como apatia generalizada da sociedade - e, em particular, do PNV - face ao autoritarismo franquista. Federico Krutwig, ideólogo da ETA e autor do livro Vasconia, publicado em 1963, uma das obras mais influentes nas primeiras décadas de vida da organização terrorista basca, acusou o lehendakari [presidente do Governo Basco] Jesús Maria Leizaola de colaborar com os inimigos do povo basco e de ser um falso nacionalista que deveria ser fuzilado, em grande medida porque, além de tido como politicamente passivo, Leizaola não ensinou euskera aos seus filhos (De Pablo, 2015, p. 361; Mees, 2003, p. 26). Xavier Zumalde, antigo membro da ETA, escreveu que o País Basco das últimas décadas de franquismo "estava mais interessado em comprar um Seat 600, ou pelo menos um televisor, do que meter-se em confusões" (De Pablo, 2018). Jokin Inza, histórico militante nacionalista e uma das figuras mais importantes da resistência ao Franquismo na região basca, referiu que muitos dos seus antigos correligionários passaram os anos finais da ditadura interessados em "viver bem" e em "dinheiro, carros e comer bem" (De Pablo, 2018). Outros nacionalistas, vinculados ou não à ETA, relatam anos de conformismo e de complacência política de um povo voluntariamente submetido às vantagens do crescimento económico. O historiador Imanol Villa (2009) refere mesmo que, na década de 1960, a sociedade basca, tal como a generalidade da sociedade espanhola, revelou "uma certa aquiescência que pode ser interpretada como uma tolerância abúlica ao regime". No seio da sociedade basca existiu, de facto, dissonância entre uma parte das elites e a generalidade da população e dos quadros do PNV.

Refira-se ainda, e por fim, que a estratégia "acción-reacción-acción" confirma as conclusões de Crenshaw quanto às razões do terrorismo. Primeiro, certifica que o terrorismo afeta as atitudes públicas de maneira positiva e negativa, ambicionando cultivar simpatias junto de potenciais apoiantes ao mesmo tempo que procura que o "inimigo" instile medo e hostilidade. Segundo, estas duas funções, inter-relacionadas, dependem de uma reação do Estado que dê publicidade ao terrorismo e que demonstre à população que as reivindicações da organização têm fundamento. A reação do Estado, que no caso espanhol se materializou em diversas operações policiais de violência indiscriminada e em episódios marcantes como o processo de Burgos, acaba por constituir um precipitante de campanhas prolongadas de violência política.

\section{Conclusão}

Ainda que duradouro e intuitivo, o argumento que atribui ao autoritarismo franquista a causa maior do aparecimento do terrorismo etarra padece de vários problemas, desde logo de falta de sustentação empírica. Não é possível afirmar que o País Basco tenha sido alvo de medidas especiais e direcionadas de repressão política nem de eliminação cultural e étnica. Tudo indica que esta região de Espanha está longe 
de ocupar os lugares cimeiros da lista no que toca a mortes e saneamentos com móbil político durante e após a Guerra Civil. Ademais, a ETA surge num momento de alguma liberalização política do regime, que se traduziu na abertura a importantes expressões culturais e nacionalistas bascas.

Mesmo reconhecendo que a opressão estatal pode ser um de vários elementos que incentivam a ocorrência de violência terrorista, a existência de uma lógica causal direta e simples teria motivado o surgimento de terrorismo no seio do nacionalismo basco décadas antes, pois os militantes desta doutrina estiveram sujeitos a pressão estatal desde que Sabino Arana inaugurou o conceito de nação basca no final do século XIX. As facetas radicais do nacionalismo basco sempre pugnaram pela independência daquela região, independentemente da natureza do regime instalado em Madrid. Note-se igualmente que parte da debilidade deste argumento reside no facto de mais de $90 \%$ das vítimas mortais da violência etarra se situarem nos anos posteriores a 1978, isto é, após o término do regime idealizado e conduzido por Francisco Franco.

A ETA parece confirmar os postulados e os eixos centrais do modelo teórico desenvolvido por Martha Crenshaw, destacando assim o terrorismo enquanto fenómeno complexo e multicausal. No caso basco, a pré-existência de uma cultura política de intransigência, assente em conceções de alteridade e de ódio, conjugada com elementos como a modernização e os seus efeitos, a dissonância entre elites e população, a perceção de injustiça e de humilhação às mãos de um agente externo identificável, e a instrumentalização eficaz da reação do Estado constituíram a base favorável à eclosão de violência política reiterada e sistematizada. Por último, decorre destes fatores e da validação do modelo de Crenshaw que o terrorismo etarra foi uma estratégia consciente, de opção racional, que não se presta a explicações e abordagens de causalidade direta e simples.

Data de receção: $31 / 01 / 2019$

Data de aprovação: 08/05/2019

\section{Referências}

Arana, S. (1887, 11 de julho). Efectos de la invasión. Baserritarra, n. ${ }^{\circ} 11$.

Arana, S. (1895, 28 de julho). El diário de Bilbao. Bizkaitarra, Ano III - n. 31.

Arana, S. (1895, 31 de novembro). Errores catalanistas. Bizkaitarra, Ano II - n.o 16.

Arana, S. (1899, 11 de junho). Regeneración. El Correo Vasco, n. ${ }^{\circ} 8$.

Barruso, P. (2005). Violencia política y represión en Guipúzcoa durante la Guerra Civil y el primer Franquismo (1936-1945). San Sebastian: Hiria Liburuak. 
Crelinsten, R. D. (2002). Analysing terrorism and counter terrorism: a communication model. Terrorism and Political Violence, 14 (2), 77-122.

Crenshaw, M. (1981). The causes of terrorism. Comparative Politics, (13), 379-399.

Crenshaw, M. (2011). Explaining terrorism. Causes, processes, and Consequences. Londres \& Nova Iorque: Routledge.

De la Calle, L. \& Sánchez-Cuenca, I. (2004). La selección de víctimas en ETA. Revista Española de Ciencia Política, (10), 53-79.

De Graaf, B. \& Malki, L., (2010). Killing it softly? Explaining the early demise of left-wing terrorism in the Netherlands. Terrorism \& Political Violence, 22 (4), 623-640.

De la Granja Sainz, J. L. (2006). El antimaketismo: La visión de Sabino Arana sobre España y los españoles. Norba-Revista de História, 19, 191-203.

De Madariaga, J. K. (1961, 3. a série, n. ${ }^{\circ}$ 17). Diálogo o violencia. Zutik.

De Pablo, S. (2015). La Patria Soñada. História del nacionalismo vasco desde su origen hasta la actualidad. Madrid: Editorial Biblioteca Nueva.

De Pablo, S. (2018). Tiempo de contrastes. El País Vasco en la década de 1960. In G. Fernandez Soldevilla \& F. Domínguez Iribarren (Eds.), Pardines. Cuando ETA empezó a matar (pp. 39-73). Madrid: Tecnos.

Elorza, A. (2009). Terrorismo e ideología. In S. Baby, O. Compagnon, \& E. G. Calleja (Eds.), Violencia y transiciones políticas a finales del siglo XX. Europa del Sur - América Latina (pp. 77-94). Madrid: Casa de Velázquez.

Espinosa Maestre, F. (2009). Sobre la represión franquista en el País Vasco”. Historia Social, (63), 59-75.

Fernandez Soldevilla, G. (2014). El simple arte de matar. Orígenes de la violencia terrorista en el País Vasco. História y Política, (32), 271-298.

Fernández Soldevilla, G., \& López Romo, R. (2012). Sangre, Votos, Manifestaciones: ETA y el nacionalismo vasco radical 1958-2011. Madrid: Tecnos.

Gibbs, J.P. (1989). Conceptualization of terrorism. American Sociological Review, 54 (3), 329_ 340.

Hoffman, B. (2006). Inside Terrorism. Nova Iorque: Columbia Press.

Huntington, S. (1965). Political Development and Political Decay. World Politics, 17 (3), 386430.

Lipset, S. (1963). Political Man. Nova Iorque: Doubleday.

López Romo, R. (2014). Informe Foronda: Los contextos históricos del terrorismo en el País Vasco y la consideración social de sus víctimas. Vitoria-Gasteiz: Instituto de Historia Social Valentín de Foronda - UPV/EHU.

Mees, L. (2003). Nationalism, Violence and Democracy. The Basque clash of identities. Nova Iorque: Palgrave Macmillan.

Molina, F. (2014). Lies of our fathers: Memory and politics in the Basque Country under the Franco dictatorship, 1936-68. Journal of Contemporary History, 49 (2), 296-319.

Reinares, F. (1998). Terrorismo y antiterrorism. Barcelona: Paidós. 
Sánchez-Cuenca, I. (2009). Analyzing temporal variation in the lethality of ETA. Revista Internacional de Sociologia, 67 (3), 609-629.

Schmid, A. P. (2004). Frameworks for conceptualizing terrorism. Terrorism and Political Violence, 16 (2), 197-221.

Schmid, A. P., \& Jongman, A. J. (1988). Political Terrorism. New Brunswick, NJ: Transaction Books.

Villa, I. (2009). Historia del País Vasco durante el franquismo. Madrid: Sílex.

Zubiaga Arana, E. (2017). La represión franquista de guerra y posguerra en el País Vasco a debate: entre el exterminio y el oasis. Historia y Política, (37), 357-384.

\section{Sobre o autor}

Diogo NoIvo é Investigador associado do Observatório Político. Diretor de research e análise de risco político no setor privado. Mestre em Segurança \& Defesa pela Universidade Complutense de Madrid e pelo Centro Superior de Estudios de la Defensa Nacional (CESEDEN) e licenciado em Ciência Política, ramo de Política Comparada, pela Universidade Lusíada de Lisboa. É membro do Advisory Board nos projetos de investigação "Psychosocial Processes and Intervention Strategies Behind Islamic Deradicalisation: a scoping review"' e "Research challenges underlying deradicalisation: a scoping review", ambos da Universidade do Porto.

\footnotetext{
About the author

DIOGo NOIvo is an Associated researcher at Observatório Político. Director of research and political risk analysis in the private sector. M.A. in Security \& Defense by Complutense University of Madrid and Centro Superior de Estudios de la Defensa Nacional (CESEDEN), and a bachelor's in Political Science-Compared Politics by Lusíada University of Lisbon. Member of the Advisory Board in the research projects "Psychosocial Processes and Intervention Strategies Behind Islamic Deradicalisation: a scoping review" and "Research challenges underlying deradicalisation: a scoping review”, both from Oporto University.
} 